\title{
Vacas lactantes alimentadas com silagem de cana-de-açúcar com e sem aditivo bacteriano: consumo, digestibilidade, produção e composição do leite ${ }^{1}$
}

\author{
Lactating cows fed with silage of sugar cane with and without additive bacterial: \\ intake, digestibility, milk production and composition
}

SANTOS, Alana Batista dos ${ }^{2 *}$; PEREIRA, Mara Lúcia Albuquerque ${ }^{3}$; AZEVEDO, Saulo Tannus ${ }^{2}$; SIGNORETTI, Ricardo Dias ${ }^{4}$; SIQUEIRA, Gustavo Resende ${ }^{4}$; MENDONÇA, Sandro de Souza ${ }^{5}$; PIRES, Aureliano José Vieira ${ }^{5}$; PEREIRA, Taiala Cristina de Jesus²; ALMEIDA, Paulo José Presídio²; RIBEIRO, Leandro Sampaio Oliveira $^{2}$; PEREIRA, César Augusto Ramos ${ }^{5}$

\footnotetext{
${ }^{1}$ Parte da dissertação de mestrado do terceiro autor.

${ }^{2}$ Universidade Estadual do Sudoeste da Bahia, Programa de Pós-Graduação em Zootecnia, Itapetinga, Bahia, Brasil.

${ }^{3}$ Universidade Estadual do Sudoeste da Bahia, Departamento de Estudos Básicos Instrumentais, Itapetinga, Bahia, Brasil.

${ }^{4}$ Agência Paulista de Tecnologia e Agronegócios, Pólo Regional de Desenvolvimento Tecnológico da Alta Mogiana, Colina, São Paulo, Brasil.

${ }^{5}$ Universidade Estadual do Sudoeste da Bahia, Departamento de Tecnologia Rural e Animal, Itapetinga, Bahia, Brasil.

*Endereço para correspondência: alanasantos10@ hotmail.com
}

\section{RESUMO}

A ensilagem de cana-de-açúcar é uma ferramenta que pode ser utilizada para atender a deficiência de alimento em períodos seco do ano, e a adição de aditivos microbianos na ensilagem pode melhorar o perfil fermentativo e, consequentemente, seu valor alimentício. $\mathrm{O}$ objetivo com o presente trabalho foi avaliar o efeito da utilização da canade-açúcar fresca ou conservada, sob a forma de silagem, com ou sem aditivo microbiano, bem como verificar a influência da queima da cana em dietas de vacas lactantes sobre o consumo e digestibilidade aparente dos nutrientes, produção e composição do leite. Os animais foram distribuídos em um quadrado latino 5 x 5 para avaliar os efeitos da cana fresca e da silagem de cana sem Lactobacillus buchneri (SCSI); cana com L. buchneri (SCCI); cana queimada sem $L$. buchneri (SCQSI); cana queimada com $L$. buchneri (SCQCI). Vacas alimentadas com cana fresca apresentaram maiores consumo de matéria seca e carboidratos não fibrosos, quando comparada com as silagens. A queima da cana e a conservação na forma de silagem, com ou sem aditivo microbiano, não alterou os consumos de matéria orgânica, proteína bruta, extrato etéreo, fibra em detergente neutro, fibra em detergente ácido, carboidratos totais, assim como, não influenciou a digestibilidade dos nutrientes dos animais. Ao alimentar vaca com silagem de cana sem aditivo bacteriano, observou-se menor produção de leite e de proteína bruta, quando comparado com as silagens queimadas com ou sem aditivo e cana fresca. Recomenda-se a utilização de cana fresca por proporcionar aos animais melhor desempenho produtivo.

Palavras-chave: Lactobacillus buchneri, produção de leite, Saccharum officinarum, vacas mestiças.

\section{SUMMARY}

The silage, sugar cane is a tool that can be used to meet the deficiency of food in the dry year and the addition of microbial silage additives can improve the fermentation and consequently, its food value. The objective was to evaluate the 
effect of the fresh sugar cane utilization or preserved as silage, with or without microbial addictive, as well as verify the influence of burning sugar cane used in diet crossbred dairy cows on intake and digestibility nutrients, production, milk composition. The animals were divided in a $5 \times 5$ latin square to evaluate the effects of fresh cane and four types of cane silage; cane without Lactobacillus buchneri (SCSI); cane with L.buchneri (SCCI); burned cane without L. buchneri (SCQSI); burned cane with L. buchneri (SCQCI). The fresh cane promotes higher dry matter intake and nonfibrous carbohydrates compared with silages. The burning of sugar cane and conservation as silage, with or without microbial additive does not alter the intake and digestibility of nutrients from animals. The use of cane ensilage without bacterial addictive provides lower milk production and crude protein when compared with the other treatments. It is recommended the use of fresh cane for providing animal better performance.

Keywords: cows, Lactobacillus buchneri, milk production, saccharum officinarum.

\section{INTRODUÇÃO}

A cana-de-açúcar fornecida fresca é, tradicionalmente, utilizada pelos pecuaristas, como alternativa alimentar bovina principalmente em períodos críticos de produção de forragem. O corte diário torna-se problemático, em situações em que se utiliza a cana como forragem durante o ano todo, devido à dificuldade de colheita, especialmente nos dias de chuva. Já o manejo industrial de canaviais exige que o corte dos talhões seja realizado de forma concentrada para aumentar a eficiência dos tratos culturais. Associado a isso, há situações em que o canavial é queimado acidentalmente ou que tenham sofrido fortes geadas. Em ambos os casos, a cana deve ser utilizada, rapidamente, para evitar perdas $\mathrm{e}$ comprometimento de sua qualidade.

A conservação da cana por meio da ensilagem, além de proporcionar homogeneização do material ensilado, liberação da área para rebrota homogênea das plantas, proporciona melhor cobertura do solo e maior índice de área foliar para o período das águas e, consequentemente, menores gastos com o controle de plantas invasoras (FREITAS et al., 2006).

$\mathrm{O}$ alto teor de carboidratos solúveis e a grande população de leveduras epífitas na sua ensilagem levam à fermentação alcoólica, o que causa perdas excessivas de matéria seca e de valor nutritivo da forragem. Dessa forma, aditivos químicos e inoculantes microbianos têm sido utilizados com o intuito de melhorar o padrão de fermentação e conservação das silagens, visto promoverem o desenvolvimento dos microrganismos benéficos, como as bactérias produtoras de ácido lático, e inibição dos indesejáveis, como as leveduras e clostrídios (FERREIRA et al., 2007).

Pedroso et al. (2006) avaliaram a utilização do L. buchneri na ensilagem da cana e observaram redução na produção de etanol, aumento da estabilidade aeróbia das silagens e incremento no ganho de peso diário de bovinos confinados. Entretanto, pesquisas que avaliaram o desempenho de ruminantes alimentados com silagens da forrageira são bastante escassos. A maioria dos estudos deteve-se no efeito do inoculante sobre o processo fermentativo e sobre as características da silagem produzida (MENDES et al., 2008).

Objetivou-se avaliar o efeito da utilização da cana-de-açúcar fresca ou conservada, sob a forma de silagem, com ou sem aditivo microbiano, bem como verificar a influência da queima da cana em dietas de vacas lactantes sobre o consumo e digestibilidade aparente dos nutrientes, produção e composição do leite. 


\section{MATERIAL E MÉTODOS}

O experimento foi conduzido no Polo Regional de Desenvolvimento Tecnológico da Alta Mogiana - APTA em Colina, SP. Foram utilizadas cinco vacas leiteiras mestiças, 3/4 Holandês $\mathrm{x}$ Gir, com média de 100 dias de lactação ao início do experimento. As dietas foram formuladas para suprir as exigências de peso corporal médio de $550 \mathrm{~kg}$ e produção média de $15 \mathrm{~kg}$ de leite por dia e consistiram em $60 \%$ de volumoso e $40 \%$ de concentrado (Tabela 1) com base na matéria seca.

Tabela 1. Composição percentual dos ingredientes no concentrado, expressa com base na matéria seca

\begin{tabular}{lc}
\hline Ingredientes & $\%$ \\
\hline Milho & 55,0 \\
Farelo de Soja & 18,9 \\
Farelo de Algodão & 18,1 \\
Ureia + Sulfato de Amônio & 3,1 \\
Fosfato Bicálcico & 1,5 \\
Calcário Calcítico & 0,9 \\
Sal Comum & 0,4 \\
Flor de Enxofre & 0,1 \\
Fosbovi 20 & 2,0 \\
\hline 'Quantidade por kg do produto (cálcio 120g, \\
iodo 75mg, fósforo 88g, manganês 1300mg, \\
sódio 126g, selênio 15mg, enxofre 12g, zinco \\
3630mg, cobalto 55,5g, flúor 880mg, cobre \\
1530mg ferro 1800mg, veículo q.s.q. 1000mg).
\end{tabular}

Os animais foram distribuídos em um quadrado latino 5 x 5 para avaliar os efeitos da cana fresca e da silagem de cana-de-açúcar sem Lactobacillus buchneri (SCSI); cana-de-açúcar com L. buchneri (SCCI); cana-deaçúcar queimada sem $L$. buchneri (SCQSI); cana-de-açúcar queimada com L. buchneri (SCQCI) (Tabela 2).
Utilizou-se a variedade IAC-86-2480, colhida quando apresentava 15 meses de período de crescimento. Foi utilizado silo tipo superfície, com capacidade para 100 toneladas de matéria natural e a quantidade de Lactobacillus buchneri utilizada foi de $5 \times 10^{4}$ ufc por grama de massa ensilada na matéria natural. Para o processo da queima, foi colocado fogo no talhão, como utilizado nas usinas de cana, que pode ser considerado também como fogo acidental.

$\mathrm{O}$ experimento foi constituído de cinco períodos experimentais com duração de 15 dias cada, os quais foram assim distribuídos: os primeiros 10 dias para adaptação as dietas (Tabela 2) e 5 dias de coletas de dados. Antes da realização da pesquisa, as vacas estavam sujeitas a pasto, com acesso a suplementação mineral. Durante experimento, os animais permaneceram em baias individuais, com cobertura, cocho e bebedouro, onde receberam o alimento na forma de mistura completa, duas vezes ao dia, após as ordenhas da manhã e da tarde com acesso ad libitum às dietas e à água.

O consumo voluntário foi calculado pela diferença entre o oferecido e as sobras. As dietas foram ajustadas para corresponderem a $10 \%$ de sobras do total oferecido. Durante os cinco dias de coletas, as sobras foram recolhidas diariamente, durante o período da manhã e da tarde, nos quais foram pesadas e amostradas em $10 \%$ do peso. Foram obtidas, para cada animal, amostras compostas de alimento fornecido e sobras referentes a cada período experimental. As análises de matéria seca (MS), proteína bruta $(\mathrm{PB})$, extrato etéreo $(\mathrm{EE})$, fibra em detergente neutro (FDN), fibra em detergente ácido (FDA), nitrogênio insolúvel em detergente neutro (NIDN), nitrogênio insolúvel em detergente ácido (NIDA), lignina e cinza foram realizadas conforme descrição de Silva \& Queiroz (2002). O teor de fibra, em detergente 
Rev. Bras. Saúde Prod. Anim., Salvador, v.13, n.3, p.720-731 jul./set., 2012 http://www.rbspa.ufba.br ISSN 15199940

neutro corrigido para cinza e proteína, foi encontrado segundo recomendações de Licitra et al. (1996) e Mertens (2002). A percentagem de carboidratos não fibrosos (CNF) foi calculada como: $\mathrm{CNF}=100-\left(\% \mathrm{FDN}_{\mathrm{cp}}+\% \mathrm{~PB}+\% \mathrm{EE}+\right.$ $\%$ cinza), conforme Hall (2003).

Os nutrientes digestíveis totais (NDT) foram calculados segundo o NRC (2001), pela seguinte equação: NDT $(\%)=$ PBD + FDND + CNFD + 2,25 x $\mathrm{EED}$, em que: $\mathrm{PBD}=$ proteína bruta digestível; FDND = fibra em detergente neutro digestível; CNFD = carboidratos não fibrosos digestíveis; e EED = extrato etéreo digestível.

Para a determinação dos coeficientes de digestibilidade aparente dos nutrientes foi utilizada a fibra, em detergente ácido indigestível (FDAi), como indicador interno, obtida após 144 h de incubação ruminal dos alimentos, sobras e fezes, que foi inserida em sacos de tecido não tecido (TNT - Gramatura 100), conforme Cochran et al. (1986).

Tabela 2. Composição nutricional do concentrado, volumosos e dietas experimentais

\begin{tabular}{|c|c|c|c|c|c|c|}
\hline \multirow[b]{2}{*}{ Item (\% MS) } & \multicolumn{5}{|c|}{ Volumosos } & \multirow[b]{2}{*}{ Concentrado } \\
\hline & $\begin{array}{l}\text { Cana } \\
\text { fresca }\end{array}$ & SCCI & SCQSI & SCSI & SCQCI & \\
\hline Matéria seca & 25,6 & 24,1 & 24,1 & 24,8 & 24,9 & 94,6 \\
\hline Matéria orgânica & 97,0 & 95,8 & 97,2 & 95,7 & 97,1 & 92,8 \\
\hline Proteína bruta & 2,4 & 3,5 & 3,5 & 3,1 & 3,0 & 29,4 \\
\hline Extrato etéreo & 1,7 & 3,5 & 3,2 & 2,8 & 2,8 & 2,5 \\
\hline Fibra em detergente neutro & 51,5 & 67,4 & 65,6 & 72,9 & 61,6 & 28,5 \\
\hline $\mathrm{FDN}_{\mathrm{CP}}$ & 47,1 & 62,8 & 60,6 & 67,4 & 57,9 & 17,5 \\
\hline Fibra em detergente ácido & 39,1 & 47,8 & 52,5 & 53,4 & 47,4 & 19,2 \\
\hline $\mathrm{NIDN}^{1}$ & 43,2 & 35,1 & 41,8 & 38,8 & 39,4 & 12,7 \\
\hline $\mathrm{NIDA}^{1}$ & 13,0 & 13,9 & 13,4 & 16,2 & 12,7 & 9,6 \\
\hline Carboidratos não fibrosos & 45,9 & 26,3 & 30,5 & 22,5 & 33,8 & 43,3 \\
\hline Carboidratos totais & 93,0 & 89,2 & 91,1 & 89,8 & 91,7 & 60,8 \\
\hline Cinza & 3,0 & 4,2 & 2,8 & 4,3 & 2,9 & 7,2 \\
\hline Lignina & 7,6 & 8,6 & 8,9 & 9,2 & 8,0 & 2,7 \\
\hline Nutrientes (\%) & \multicolumn{5}{|c|}{ Rações } & \\
\hline Matéria seca & 53,2 & 52,3 & 52,3 & 52,7 & 52,8 & --- \\
\hline Matéria orgânica & 95,3 & 94,6 & 95,4 & 94,5 & 95,4 & --- \\
\hline Proteína bruta & 13,2 & 13,9 & 13,7 & 13,6 & 13,5 & --- \\
\hline Extrato etéreo & 2,00 & 3,10 & 2,90 & 2,70 & 2,70 & --- \\
\hline Fibra em detergente neutro & 42,3 & 51,8 & 50,7 & 55,1 & 48,3 & --- \\
\hline $\mathrm{FDN}_{\mathrm{CP}}$ & 35,3 & 44,7 & 43,4 & 47,4 & 41,7 & --- \\
\hline Fibra em detergente ácido & 31,1 & 36,4 & 39,2 & 39,7 & 36,1 & --- \\
\hline $\mathrm{NIDN}^{1}$ & 31,0 & 26,1 & 30,2 & 28,4 & 28,7 & --- \\
\hline $\mathrm{NIDA}^{1}$ & 11,6 & 12,2 & 11,9 & 13,6 & 11,5 & --- \\
\hline Carboidratos não fibrosos & 44,8 & 33,1 & 35,6 & 30,8 & 37,6 & --- \\
\hline Carboidratos totais & 80,1 & 77,8 & 79,0 & 78,2 & 79,3 & --- \\
\hline Cinza & 4,60 & 5,40 & 4,50 & 5,50 & 4,60 & --- \\
\hline Lignina & 5,70 & 6,30 & 6,40 & 6,60 & 5,90 & --- \\
\hline Nutrientes digestíveis totais & 60,0 & 59,0 & 56,8 & 54,9 & 55,0 & --- \\
\hline
\end{tabular}

${ }^{\mathrm{I}}$ Expresso como porcentagem do N-total; SCSI = silagem de cana-de-açúcar sem L. buchneri; SCCI = silagem de cana-de-açúcar com $L$. buchneri; SCQSI = silagem de cana-de-açúcar queimada sem $L$. buchneri; $\mathrm{SCQSI}=$ silagem de cana-de-açúcar queimada com $L$. buchneri; FDNcp = fibra em detergente neutro corrigido para cinza e proteína; NIDN = nitrogênio insolúvel em detergente neutro; NIDA = nitrogênio insolúvel detergente ácido. 
As vacas foram ordenhadas, mecanicamente, duas vezes ao dia, e o registro da produção de leite foi feito do $11^{\circ}$ ao $15^{\circ}$ dia de cada período experimental. Foram coletadas amostras de leite, no $11^{\circ}$ dia à tarde e no $12^{\circ}$ pela manhã, de cada período, e fizeram-se amostras compostas de $1 \%$ da produção para análises da composição do leite. As análises qualitativas do leite foram realizadas no Laboratório de Fisiologia da Lactação da Escola Superior Luiz de Queiroz (ESALQ), em Piracicaba-SP, por meio da metodologia da AOAC (1990). A produção de leite foi corrigida para 3,5\% de gordura (PLG), pela equação citada por Sklan et al. (1992): PLG $=(0,432+0,1625 \times \mathrm{x}) \times$ $\mathrm{kg}$ de leite, em que $\mathrm{G}=\%$ de gordura do leite.

As variáveis dependentes foram estudadas por meio de análise de variância a $5 \%$ de probabilidade e, quando detectadas diferenças entre tratamentos, foi aplicado o teste Tukey, utilizando o Sistema para Análise Estatística - SAEG (UFV, 2001).

\section{RESULTADOS E DISCUSSÃO}

O consumo de matéria seca da cana fresca foi superior ao das silagens de cana-de-açúcar com e sem L. buchneri (Tabela 3). As silagens apresentaram teores de fibra em detergente neutro mais elevado, fato que explica, possivelmente, o menor consumo de matéria seca resultante para as silagens.

A elevação percentual das frações fibra em detergente neutro e fibra em detergente ácido em relação à cana fresca foi, respectivamente, de 22,3 e $22,2 \%$ (Tabela 2). Dessa forma, o consumo de matéria seca (kg/dia) reduziu $21,15 \%$ da silagem $v s$ cana fresca, provavelmente, em decorrência da perda fermentativa de carboidratos solúveis na ensilagem (Tabela 3). De acordo com Schmidt et al. (2007), o aumento relativo nos teores de componentes da fração fibrosa pode estar associada à perda de carboidrato solúvel sem constituir redução de matéria seca, uma vez que parte dos carboidratos solúveis é convertida a ácidos orgânicos.

Siqueira et al. (2007), ao trabalharem com a associação entre aditivos químicos e bacterianos na ensilagem de cana-de-açúcar, notaram elevação no teor de fibra em detergente neutro de $55,1 \%$ no momento da ensilagem para $66,9 \%$ após abertura. Neste estudo houve uma variação de fibra em detergente neutro da cana fresca e das silagens, que pode ser resultado da utilização de carboidratos não fibrosos pelo processo de fermentação.

Os animais utilizados nesta pesquisa, encontravam-se no estádio médio de lactação, período em que ocorre diminuição na produção de leite e aumento no consumo de matéria seca. Entretanto, verificou-se que a silagem de cana aditivada, ou não, proporcionou diminuição na ingestão de matéria seca (Tabela 3). Dessa forma, pode-se pressupor que o enchimento físico limitou o consumo dos animais, que se alimentaram com as silagens.

Geralmente, ocorre aumento de consumo com elevação do peso corporal, o que indica ser mais conveniente expressar o consumo em função do peso vivo. Entretanto, observou-se que os resultados foram semelhantes para as três formas de expressão do consumo, de modo a comprovar que as diferenças observadas entre os valores médios dos consumos de matéria seca resultaram do efeito positivo da utilização da cana fresca na dieta. 
Rev. Bras. Saúde Prod. Anim., Salvador, v.13, n.3, p.720-731 jul./set., 2012 http://www.rbspa.ufba.br ISSN 15199940

Tabela 3. Consumo médio de matéria seca e nutrientes, em $\mathrm{Kg} / \mathrm{dia}, \% \mathrm{PV}$ e em g/PV 0,75 em função das diferentes dietas

\begin{tabular}{|c|c|c|c|c|c|c|c|}
\hline \multirow[b]{2}{*}{ Item } & \multicolumn{5}{|c|}{ Dietas } & \multirow[b]{2}{*}{$\begin{array}{l}\mathrm{CV} \\
(\%)\end{array}$} & \multirow{2}{*}{$\begin{array}{c}\text { Valor } \\
\text { P }\end{array}$} \\
\hline & $\begin{array}{l}\text { Cana } \\
\text { fresca }\end{array}$ & SCCI & SCQSI & SCSI & SCQCI & & \\
\hline Matéria seca & $15,4^{\mathrm{a}}$ & $12,7^{\mathrm{b}}$ & $11,1^{b}$ & $11,8^{\mathrm{b}}$ & $12,8^{b}$ & 8,5 & 0,0006 \\
\hline Matéria orgânica & 13,7 & 11,7 & 10,9 & 11,5 & 12,4 & 15,3 & n.s. \\
\hline Proteína bruta & 2,1 & 1,9 & 1,8 & 1,8 & 1,9 & 18,1 & n.s. \\
\hline Extrato etéreo & 0,3 & 0,4 & 0,3 & 0,3 & 0,3 & 16,0 & n.s. \\
\hline Fibra em detergente neutro & 5,6 & 6,1 & 5,5 & 6,4 & 6,0 & 15,2 & n.s. \\
\hline Fibra em detergente ácido & 4,7 & 4,9 & 4,2 & 5,3 & 5,1 & 20,3 & n.s. \\
\hline Carboidratos não fibrosos & $6,7^{\mathrm{a}}$ & $4,0^{\mathrm{b}}$ & $4,0^{\mathrm{b}}$ & $3,8^{\mathrm{b}}$ & $4,9^{\mathrm{b}}$ & 16,1 & 0,0003 \\
\hline Carboidratos totais & 11,2 & 9,4 & 8,8 & 9,4 & 10,1 & 15,2 & n.s. \\
\hline \multirow[t]{2}{*}{ Nutrientes digestíveis totais } & 10,0 & 8,4 & 7,4 & 7,3 & 7,8 & 20,1 & n.s. \\
\hline & \multicolumn{5}{|c|}{ Consumo (\% Peso vivo) } & & \\
\hline Matéria seca & $3,3^{\mathrm{a}}$ & $2,7^{\mathrm{b}}$ & $2,4^{\mathrm{b}}$ & $2,5^{b}$ & $2,8^{\mathrm{b}}$ & 8,6 & 0,0005 \\
\hline Fibra em detergente neutro & 1,2 & 1,3 & 1,2 & 1,4 & 1,3 & 16,1 & n.s. \\
\hline \multirow[t]{2}{*}{ Carboidratos não fibrosos } & $1,5^{\mathrm{a}}$ & $0,8^{\mathrm{b}}$ & $0,9^{\mathrm{b}}$ & $0,8^{\mathrm{b}}$ & $1,1^{\mathrm{b}}$ & 14,8 & 0,0001 \\
\hline & \multicolumn{5}{|c|}{ Consumo $\left(\mathrm{g} / \mathrm{PV}^{0,75}\right)$} & & \\
\hline Matéria seca & $155,1^{\mathrm{a}}$ & $126,8^{b}$ & $112,7^{\mathrm{b}}$ & $118,3^{b}$ & $127,8^{b}$ & 8,5 & 0,0005 \\
\hline Carboidratos não fibrosos & $69,0^{\mathrm{a}}$ & $39,8^{\mathrm{b}}$ & $41,3^{\mathrm{b}}$ & $37,8^{\mathrm{b}}$ & $49,6^{\mathrm{b}}$ & 14,6 & 0,0001 \\
\hline
\end{tabular}

n.s. $=$ não significaivo $(\mathrm{P}>0,05)$ pela $A N O V A ; C V=$ coeficiente de variação; Valor de $\mathrm{P}=$ probabilidade de ANOVA; $\mathrm{a} b \mathrm{c}=$ médias seguidas por letras diferentes diferem pelo teste de Tukey $(\mathrm{P}<0,05)$; $\mathrm{SCSI}=$ cana-de-açúcar sem Lactobacillus buchneri; SCCI = cana-de-açúcar com L. buchneri; SCQSI = cana-deaçúcar queimada sem L. buchneri; $\mathrm{SCQCI}$ = cana-de-açúcar queimada com L. buchneri.

O modelo fibra em detergente neutro consumo de energia, citado por Mertens (1994), prevê que a ingestão seja limitada pelo enchimento do rúmem, quando o consumo diário de fibra em detergente neutro é maior que 11 a $13 \mathrm{~g} / \mathrm{kg}$ do $\mathrm{PV}$. Dessa forma, nesta pesquisa, o consumo de fibra em detergente neutro ficou sitado acima da capacidade ótima do consumo de fibra, pois variou de 11,9 a $13,7 \mathrm{~g} / \mathrm{kg}$ $\mathrm{PV}$, o que tornou possível confirmar que o controle de ingestão de alimentos dos animais utilizados nesta pesquisa foi físico. Os resultados verificados para o consumo de matéria seca também corroboram com esta afirmação, uma vez que as silagens, por conterem concentração mais elevada de fibra em detergente neutro, proporcionaram menores consumo de matéria seca aos animais, quando comparado com a cana fresca.
O consumo médio de carboidratos não fibrosos, nas três formas de expressão, a cana fresca diferiu $(\mathrm{P}<0,05)$ das silagens. $\mathrm{O}$ inferior consumo de carboidrato não fibroso (redução média de $37,2 \%$ ) encontrado para as silagens é correspondente ao menor consumo de matéria seca, quando comparado com a cana fresca, e à redução de seus teores $(23,5 \%)$ no processo de fermentação das silagens utilizadas na dieta.

Mesmo com redução dos teores de carboidratos não fibrosos nas dietas, compostas de silagem de cana, os teores de carboidratos totais não se alteraram entre estas, o que refletiu na semelhança $(\mathrm{P}>0,05)$ de seu consumo. Da mesma forma que para os consumos de matéria orgânica, proteína bruta e extrato etéreo não foram constatados diferenças entre composições alimentares. 
A ausência de diferença estatística para o consumo de nutrientes digestíveis totais entre as rações pode ser justificada pelo alto coeficiente de variação encontrado $(20,02 \%)$. O consumo de nutrientes digestíveis totais com cana fresca foi de $10,02 \mathrm{~kg} /$ dia e o da silagem de cana-deaçúcar sem inoculante, 7,26 kg/dia, com uma diferença de 2,76kg/dia. Contudo, não havia equilíbrio no NDT das rações. Resultado semelhante foi verificado por Martins et al. (2011) que, em pesquisa com vacas mestiças Holandês x Gir, alimentadas com diferentes volumosos (cana-de-açúcar, silagem de sorgo, silagem de girassol ou pasto de capimtanzânia), com produção de leite média de $13,65 \mathrm{~kg} / \mathrm{dia}$, encontraram para os animais alimentados com cana - de- açúcar, consumo de nutrientes digestíveis totais de $11,9 \mathrm{~kg} / \mathrm{dia}$.

Não foram verificadas diferenças $(\mathrm{P}>0,05)$ para a digestibilidade aparente das dietas compostas de cana fresca e silagens com e sem L. buchneri. Os valores dos coeficientes calculados, mediante utilização do indicador fibra em detergente neutro indigestível, não foram tão conflitantes entre as diferentes dietas, somente, para extrato etéreo e carboidratos não fibrosos. A digestibilidade aparente média do extrato etéreo e carboidratos não fibrosos foi de 58,1 e $96,2 \%$ respectivamente, (Tabela 4), as quais se aproximam daquelas observadas por Cordeiro et al. (2007), que encontraram média de 52,5\% e $93,8 \%$ e consumos de tais nutrientes de 0,21 e $5,16 \mathrm{~kg} /$ dia.

Tabela 4. Coeficiente de digestibilidade dos nutrientes em função das dietas experimentais

\begin{tabular}{|c|c|c|c|c|c|c|}
\hline \multirow[b]{2}{*}{ Nutrientes } & \multicolumn{5}{|c|}{ Dietas } & \multirow{2}{*}{$\begin{array}{l}\mathrm{CV} \\
(\%)\end{array}$} \\
\hline & $\begin{array}{l}\text { Cana } \\
\text { fresca }\end{array}$ & SCCI & SCQSI & SCSI & SCQCI & \\
\hline Matéria seca & 55,6 & 55,3 & 48,5 & 46,2 & 44,5 & 13,3 \\
\hline Matéria orgânica & 55,8 & 55,8 & 52,2 & 49,7 & 47,4 & 11,7 \\
\hline Proteína Bruta & 59,0 & 68,1 & 64,0 & 65,0 & 58,5 & 15,2 \\
\hline Extrato etéreo & 57,4 & 56,7 & 59,7 & 57,0 & 59,5 & 13,2 \\
\hline Fibra detergente neutro & 21,5 & 29,2 & 23,1 & 24,5 & 14,8 & 50,3 \\
\hline Fibra em detergente ácido & 29,0 & 30,2 & 23,2 & 27,0 & 20,8 & 40,3 \\
\hline Carboidratos não fibrosos & 96,7 & 97,5 & 95,9 & 96,5 & 94,3 & 2,8 \\
\hline Carboidratos totais & 55,0 & 52,8 & 48,9 & 46,5 & 44,7 & 11,5 \\
\hline Nutrientes digestíveis totais & 60,0 & 59,0 & 56,4 & 54,9 & 55,0 & 57,2 \\
\hline
\end{tabular}

$\mathrm{CV}=$ coeficiente de variação; $\mathrm{a} \mathrm{b} \mathrm{c}=$ médias seguidas por letras diferentes diferem pelo teste de Tukey $(\mathrm{P}<0,05)$; SCSI = cana-de-açúcar sem Lactobacillus buchneri; $\mathrm{SCCI}=$ cana-de-açúcar com L. buchneri; SCQSI = cana-de-açúcar queimada sem $L$. buchneri; $\mathrm{SCQCI}=$ cana-de-açúcar queimada $\operatorname{com} L$. buchneri.

O coeficiente de digestibilidade da proteína bruta não diferiu $(\mathrm{P}>0,05)$ entre as dietas experimentais e apresentou valor médio de 62,9\% (Tabela 4). É importante ressaltar que os teores de proteína bruta entre os volumosos foram semelhantes e apresentaram média de $3,5 \%$ da MS, enquanto que o concentrado conteve $29,4 \%$. Entretanto, a cana fresca e as silagens pouco contribuíram para $\mathrm{o}$ teor de proteína bruta na dieta. Dessa forma, acredita-se que isso contribuiu 
para as semelhanças no consumo e digestibilidade da proteína bruta.

Não houve diferença $(\mathrm{P}>0,05)$ entre os valores médios de nutrientes digestíveis totais das dietas em função dos diferentes volumosos utilizados (Tabela 4). A média de $57,1 \%$ de nutrientes digestíveis totais estimados por meio de ensaio de digestibilidade, com o indicador fibra em detergente ácido indigestível, foi próximo aos $60 \%$ preditos para a formulação das dietas experimentais.

A utilização de $L$. buchneri na ensilagem de cana-de-açúcar não melhorou o consumo e digestibilidade de matéria seca e nutrientes de vacas no terço médio de lactação. Os resultados de produção de leite mostram que a cana fresca e as silagens com inóculo foram semelhantes entre si. Porém, a de produção de leite corrigida para $3,5 \%$ de gordura, revelou que a silagem de cana-de-açúcar queimada sem $L$. buchneri foi o único volumoso que diferiu da cana fresca (Tabela 5).

Alterações no consumo de matéria seca têm sido relacionadas, em alguns trabalhos, como responsáveis pela alteração na produção de leite. Neste estudo, como observado, houve efeito dos tratamentos sobre o consumo de matéria seca (Tabela 3) que refletiu de forma semelhante sobre a secreção de leite (Tabela 5).

Observou-se que o teor de proteína bruta do leite foi diferente $(\mathrm{P}>0,05)$ entre as dietas e os animais alimentados com cana fresca apresentaram maior secreção de proteína no leite (Tabela 5). Isso pode ser explicado, pelo fato da dieta cana fresca apresentar consumo de carboidratos não fibrosos mais elevados (Tabela 4), que a depender do sincronismo entre energia e proteína, proporciona aos animais, maior síntese de proteína microbiana e, consequentemente, secreções mais elevadas de proteína no leite.

$\mathrm{O}$ teor de proteína bruta associado à produção de leite, possivelmente, contribuiu para as maiores produções de sólidos totais e extrato seco desengordurado, observadas para as dietas compostas de cana fresca e silagem de cana-de-açúcar queimada com inoculante.

Observou-se que a secreção de gordura no leite e sua produção não diferiram entre as rações (Tabela 5). O valor médio encontrado neste estudo $(3,7 \%)$ foi semelhante à média de 3,9\% verificada por Costa et al. (2009), que utilizaram em dietas de vacas lactantes a cana-deaçúcar, como volumoso, associado a diferentes níveis de concentrado $(0 ; 16$; 24 e $30 \%$ ).

Entre os dois parâmetros (proteína e gordura) o teor de gordura é mais facilmente alterado pela nutrição, enquanto a proteína, em casos extremos, varia cerca de $0,4 \%$ e a gordura pode variar entre 2 ou $3 \%$. Assim como a proteína, o teor de lactose do leite é dificilmente alterado. Dessa forma, os percentuais de lactose no leite das dietas experimentais não diferiram entre si ( $\mathrm{P}>0,05$ ), com média de 4,5\% (Tabela 5).

A amplitude de variação do teor de proteína bruta de $0,2 \%$ resultou em diferença estatística $(\mathrm{P}<0,05)$ entre os dados obtidos com os diferentes volumosos. Queiroz et al. (2008) avaliaram o desempenho de vacas de alta produção, alimentadas com $60 \%$ de concentrado e $40 \%$ de cana $(15,01 \%$ PB) ou $40 \%$ de silagem de cana com $L$. buchneri $(13,96 \%$ PB), e observaram, respectivamente, diferentes produções de leite de 22,3 e $23,5 \mathrm{~kg} /$ dia com teores similares de 3,24 e 3,17\% para o teor de proteína bruta e de 4,27 e 4,26\% para lactose, cujos teores são inferiores aos observados para a dieta com cana fresca deste trabalho. 
Tabela 5. Produção de leite e constituintes químicos em função das diferentes dietas

\begin{tabular}{|c|c|c|c|c|c|c|c|}
\hline \multirow{2}{*}{ Item } & \multicolumn{5}{|c|}{ Dietas } & \multirow{2}{*}{$\begin{array}{l}\mathrm{CV} \\
(\%)\end{array}$} & \multirow{2}{*}{ Valor- P } \\
\hline & Cana fresca & SCCI & SCQSI & SCSI & SCQCI & & \\
\hline PL (kg/dia) & $13,5^{\mathrm{a}}$ & $12,2^{\mathrm{abc}}$ & $11,6^{\mathrm{bc}}$ & $11,3^{\mathrm{c}}$ & $12,9^{\mathrm{ab}}$ & 6,4 & 0,0043 \\
\hline PLG (kg/dia) & $13,7^{\mathrm{a}}$ & $12,8^{\mathrm{ab}}$ & $11,8^{\mathrm{b}}$ & $12,1^{\mathrm{ab}}$ & $13,2^{\mathrm{ab}}$ & 6,4 & 0,0161 \\
\hline EA (kg leite/kg CMS) & 0,89 & 1,00 & 1,05 & 0,97 & 1,02 & 11,5 & n.s \\
\hline $\mathrm{EN}(\mathrm{kg} \mathrm{N}$ leite/kg CN) & 0,221 & 0,197 & 0,200 & 0,187 & 0,206 & 18,0 & n.s \\
\hline Gordura (\%) & 3,6 & 3,8 & 3,6 & 3,9 & 3,6 & 5,6 & n.s \\
\hline Gordura (g/dia) & 483,7 & 461,8 & 415,5 & 445,2 & 468,8 & 7,4 & n.s \\
\hline Proteína bruta (\%) & $3,3^{\mathrm{a}}$ & $3,1^{\mathrm{b}}$ & $3,1^{\mathrm{b}}$ & $3,1^{\mathrm{b}}$ & $3,1^{\mathrm{b}}$ & 2,3 & 0,0024 \\
\hline Proteína bruta (g/dia) & $445,2^{\mathrm{a}}$ & $374,0^{\mathrm{bc}}$ & $358,3^{\mathrm{bc}}$ & $349,0^{\mathrm{c}}$ & $404,1^{\mathrm{ab}}$ & 6,4 & 0,0003 \\
\hline Lactose (\%) & 4,5 & 4,5 & 4,5 & 4,4 & 4,5 & 1,8 & n.s \\
\hline Lactose (g/dia) & $601,7^{\mathrm{a}}$ & $548,2^{\mathrm{ab}}$ & $521,1^{\mathrm{ab}}$ & $500,2^{\mathrm{b}}$ & $576,9^{\mathrm{ab}}$ & 8,2 & 0,0242 \\
\hline Sólidos totais (\%) & 12,26 & 12,24 & 12,05 & 12,32 & 12,14 & 1,6 & n.s \\
\hline Sólidos totais (g/dia) & $1661,4^{\mathrm{a}}$ & $1490,1^{\mathrm{ab}}$ & $1396,4^{b}$ & $1393,9^{b}$ & $1565,5^{\mathrm{ab}}$ & 6,5 & 0,0042 \\
\hline $\operatorname{ESD}(\%)$ & $8,71^{\mathrm{a}}$ & $8,46^{\mathrm{b}}$ & $8,46^{\mathrm{b}}$ & $8,40^{\mathrm{b}}$ & $8,51^{\mathrm{ab}}$ & 1,3 & 0,0069 \\
\hline ESD (g/dia) & $1177,7^{\mathrm{a}}$ & $1028,2^{b}$ & $980,8^{\mathrm{b}}$ & $948,8^{\mathrm{b}}$ & $1096,6^{\mathrm{ab}}$ & 7,1 & 0,0025 \\
\hline NUL (mg/dl) & 17,3 & 14,3 & 17,0 & 17,2 & 17,1 & 15,8 & n.s. \\
\hline
\end{tabular}

n.s.= não significativo $(\mathrm{P}>0,05)$ pela a ANOVA; $\mathrm{CV}=$ coeficiente de variação; Valor de $\mathrm{P}=$ probabilidade da ANOVA; a b c $=$ médias seguidas de letras diferentes diferem pelo teste tukey $(\mathrm{P}<0,05)$; SCSI = silagem de cana-de-açúcar sem L. buchneri; $\mathrm{SCCI}=$ silagem de cana-de-açúcar com $L$. buchneri; SCQSI = silagem de cana-de-açúcar queimada sem $L$. buchneri; SCQSI = silagem de cana-de-açúcar queimada com L. buchneri; PL = produção de leite; PLG = produção de leite corrigido para 3,5\% de gordura; $\mathrm{EA}=$ eficiência alimentar; $\mathrm{EN}=$ eficiência de conversão de nitrogênio; $\mathrm{ESD}=$ extrato seco desengordurado; NUL = nitrogênio ureico no leite. 
A semelhança na eficiência alimentar (Tabela 5) indica que mesmo com o maior consumo de matéria seca, a dieta composta de cana fresca não resultou na mais alta eficiência de conversão em leite. Esses resultados, provavelmente, devemse à semelhança entre as digestibilidade da matéria seca e nutrientes digestíveis totais. Os resultados de conversão de compostos nitrogenados consumidos em nitrogênio do leite foram similares entre as dietas, o que indica que a utilização de nitrogênio da dieta com cana fresca não diferiu das demais, mesmo que o consumo de carboidratos não fibrosos tenha sido mais elevado. Geralmente, dietas com menor conteúdo proteico resultam na mais alta eficiência para conversão de nitrogênio dietético em nitrogênio do leite (PEREIRA et al., 2005).

Os teores de nitrogênio ureico no leite não diferiram $(\mathrm{P}>0,05)$ entre os volumosos utilizados, verifica-se que a média observada nesse estudo de $16,6 \mathrm{mg} / \mathrm{dl}$ é superior ao valor de $10,39 \mathrm{mg} / \mathrm{dl}$ verificado por Cordeiro et al. (2007), ao utilizar dieta formada por $13,0 \%$ de PB e $60 \%$ de cana-de-açúcar e $40 \%$ de concentrado a base fubá de milho e farelo de algodão.

Os teores de nitrogênio ureico no leite encontram-se próximos ao limite máximo estabelecido por Jonker et al. (1999), que relataram que a concentração de nitrogênio ureico no leite deve variar de 10 a $16 \mathrm{mg} / \mathrm{dl}$ a depender do nível de produção, pois valores acima desse limite podem indicar elevados consumo de nitrogênio ou excesso de proteína degradável no rúmem.

A queima da cana e a conservação na forma de silagem, com ou sem aditivo microbiano, não melhora o consumo e digestibilidade dos nutrientes dos animais. A utilização de silagem de cana sem aditivo bacteriano proporciona menor produção de leite e de proteína bruta, quando comparado com silagem com aditivo, silagem queimada com e sem aditivo e cana fresca. Recomendase a utilização de cana fresca por proporcionar aos animais melhor desempenho produtivo.

\section{REFERÊNCIAS}

ASSOCIATION OF OFFICIAL ANALYTICAL CHEMIST - AOAC. Official methods of analysis. 15th.ed. Chemist, Arlington, 1990.

COCHRAN, R.C.; ADAMS, D.C.; WALLACE, J.D.; GALYEAN, M.L. Predicting digestibility of different diets with internal markers: evaluation of four potential markers. Journal Dairy Science, v.63, p.1476-1483, 1986.

CORDEIRO, C.F.A.; PEREIRA, M.L.A; MENDONÇA, S.S.;

ALMEIDA, P.J.P.; AGUIAR, L.V.; FIGUEIREDO, M.P. Consumo e digestibilidade total dos nutrientes e produção e composição do leite de vacas alimentadas com teores crescentes de proteína bruta na dieta contendo cana-de-açúcar e concentrados. Revista Brasileira de Zootecnia, v.36, p.21182126, 2007.

COSTA, L.T.; SILVA, F. F.; VELOSO, C.M.; PIRES, A. J. V.; ROCHA NETO, A. L.; BONOMO, P.; MENDES, F.B.L.; OLIVEIRA, J.S.; AZEVEDO, S.T.; SILVA, V.L. Teores de concentrado em dietas a base de canade-açúcar para vacas mestiças em lactação. Revista Brasileira de Saúde e Produção Animal [Online], v.10, n.4, p.1019-1031, 2009. 
FERREIRA, D.A.; GONÇALVES, L.C.; MOLINA, L.R.; CASTRO NETO, A.G.; TOMICH, T.R. Características de fermentação da silagem de cana-deaçúcar tratada com uréia, zeólita, inoculante bacteriano e inoculante bacteriano/enzimático. Arquivos Brasileiro Medicina Veterinária e Zootecnia, v.59, p.423-433, 2007.

FREITAS, A.W.P.; PEREIRA, J.C.; ROCHA, F.C.; DETMANN, E.; RIBEIRO, M.D.; COSTA, M.G.; LEONEL, F.P. Características da silagem de cana-de-açúcar tratada com inoculante bacteriano e hidróxido de sódio e acrescida de resíduo da colheita de soja. Revista Brasileira de Zootecnia, v.35, p.48-59, 2006.

HALL, M.B. Challenges with non-fiber carbohydrate methods. Journal of Animal Science, v.81, n.12, p.32263232, 2003.

JONKER, J.S.; KOHN, R.A.; ERDMAN, R.A. Milk urea nitrogen target concentrations for lactating dairy cows fed according to national research council recommendations. Journal Dairy

Science, v.82, p.1261-1273, 1999.

LICITRA, G.; HERNANDEZ, T.M.; VAN SOEST, P.J. Standardization of procedures for nitrogen fracionation of ruminant feed. Animal Feed Science and Technology, v.57, p.347-358, 1996.

MARTINS, S.C.S.G.; ROCHA JÚNIOR, V.R.; CALDEIRA, L.A.; PIRES, D.A.A.; BARROS, I.C.; SALES, E.C.J.; SANTOS, C.C.R.; AGUIAR, A.C.R.; OLIVEIRA, C.R. Consumo, digestibilidade, produção de leite e análise econômica de dietas com diferentes volumoso. Revista Brasileira de Saúde e Produção Animal, v.12, n.3, p.691-708, 2011.
MENDES, C.Q.; SUSIN, I.; PIRES, A.V.; NUSSIO, L.G.; ARAÚJO, R.C.; RIBEIRO, M.F. Desempenho, parâmetros da carcaça e comportamento ingestivo de cordeiros alimentados com cana-de-açúcar ensilada ou in natura.

Arquivo Brasileiro de Medicina Veterinária e Zootecnia, v. 60, n.3, p. 733-740, 2008.

MERTENS, D.R. Gravimetric determination of amylase-treated neutral detergent fiber in feeds with refluxing in beakers or crucibles: collaborative study. Jounal AOAC International, v.85, p.1217-1240, 2002.

MERTENS, D.R. Regulation of forage intake. In: FAHEY, JUNIOR. (Ed.). Forage quality, evaluation and utilization. Madison: American Society of Agronomy, 1994. p.450-493.

PEDROSO, A.F.; NUSSIO, L.G.; BARIONI, JÚNIOR, W.; RODRIGUES, A.A.; LOURES, D.R.S.; CAMPOS, F.; RIBEIRO, J.L.; MARI, L.J.; ZOPOLLATTO, M.; JUNQUEIRA, M.; PAZIANI, S.; HORII, J. Performance of Holstein heifers fed sugarcane silages treated with urea, sodium benzoate or Lactobacillus bucheneri. Pesquisa Agropecuária Brasileira, v.41, n.4, p.649-654, 2006.

PEREIRA, M.L.A; VALADARES FILHO, S.C; VALADARES, R.F.D.; CAMPOS, J.M.S.; LEÃO, M.I.; PEREIRA, C.A.R.; SILVA, P.A.; MENDONÇA, S.S. Consumo, digestibilidade aparente total, produção e composição do leite em vacas no terço médio da lactação alimentadas com níveis crescentes de proteína bruta no concentrado, Revista Brasileira de Zootecnia, v.34, n.3, p.1040-1050, 2005 . 
QUEIROZ, O.C.M.; NUSSIO, L.G.;

SCHMIDT, P.; RIBEIRO, J.L.;

SANTOS, M.C.; ZOPOLLATTO, M.

Silagem de cana-de-açúcar comparada a fontes tradicionais de volumosos suplementares no desempenho de vacas de alta produção. Revista Brasileira de Zootecnia, v.37, n.2, p.358-365, 2008.

SCHMIDT, P.; MARI, L.J.; NUSSIO, L.G.; PEDROSO, A.F.; PAZIANI, S.F.; WECHSLER, F.S. Aditivos químicos e biológicos na ensilagem de cana-deaçúcar: composição química das silagens, ingestão, digestibilidade e comportamento ingestivo. Revista Brasileira de Zootecnia, v.36, n.5, p.1666-1675, 2007. Supl.

SILVA, D.J.; QUEIROZ, A.C. Análise de alimentos: métodos químicos e biológicos. Viçosa, MG: Universidade Federal de Viçosa, 2002. 235p.
SIQUEIRA, G.R.; REIS, R.A.; SCHOCKEN-ITURRINO, R.P.; BERNADES, T.F.; PIRES, A.J.V.; ROTH, M.T.P.; ROTH, A.P.T.P. Associação entre aditivos químicos e bacterianos na ensilagem de cana-deaçúcar. Revista Brasileira de Zootecnia, v.36, n.4, p.789-798, 2007.

SKLAN, D.; ASHKENAZI, R.; BRAUN, A.; DEVORIN, A.; TABORI, K. Fatty acids, calcium soaps of fatty acids, and cottonseeds fed to high yielding cows. Journal Dairy Science, v.75, n. 9, p.2463-2472, 1992.

UNIVERSIDADE FEDERAL DE VIÇOSA - UFV. Sistema para análise estatística e genética- SAEG. Versão 8.0. Viçosa, MG: Fundação Arthur Bernardes, 2001. 150p.

Data de recebimento: 03/09/2011

Data de aprovação: 03/05/2012 